Research Article

\title{
A cross-sectional study to assess the rationality of fixed dose combinations prescribed in geriatric patients in a tertiary care hospital
}

\author{
Ahish Dakappa ${ }^{1}$, Mukunda Narayanareddy ${ }^{2} *$
}

\author{
${ }^{1} 6^{\text {th }}$ Term MBBS Student, M. S. \\ Ramaiah Medical College, \\ Bangalore, India \\ ${ }^{2}$ Assistant Professor, \\ Department of Pharmacology, \\ M. S. Ramaiah Medical College, \\ Bangalore, India
}

Received: 14 May 2016

Accepted: 09 June 2016

*Correspondence to:

Dr. Mukunda Narayanareddy, Email: drmukundagm@ gmail.com

Copyright: (๑) the author(s), publisher and licensee Medip Academy. This is an openaccess article distributed under the terms of the Creative Commons Attribution NonCommercial License, which permits unrestricted noncommercial use, distribution, and reproduction in any medium, provided the original work is properly cited.

\begin{abstract}
Background: There is a growing concern about use of irrational fixed dose combinations (FDC) in geriatric patients which imposes unnecessary financial burden, increase the occurrence of adverse drug reactions, hospitalization and ultimately reducing the quality of life. The aim of our study is to assess prescription rate of irrational FDCs in geriatric patients in our hospital.

Methods: A cross sectional observational study was carried out at M. S. Ramaiah hospital for a period of 2 months and the case records of patients aged $\geq 60$ years visiting various departments were retrieved from medical record section. We reviewed their prescriptions and analysed the prescription rate of FDCs and their rationality was assessed by using WHO guidelines for FDCs. Descriptive statistics were used to analyse the data. SPSS Version 20 was used for statistical analysis.

Results: We studied case files of 361 geriatric patients who visited our hospital during our study period. Among them 212 (58.7\%) were male and $149(41.3 \%)$ were female patients. Prescription rate of FDCs in our study was $69.8 \%$. A total of 82 FDCs were prescribed in our study. Among these 82 FDCs, 56 (68.3\%) were irrational as per WHO guidelines. The commonly prescribed FDCs in our study were combination of anti-asthmatic drugs, multivitamin preparations, antihypertensive combinations, analgesics, and antimicrobial agents.

Conclusions: The prescription rate of irrational FDCs is very high in our hospital. There is a need to educate physicians regarding consequences of use of such irrational FDCs.
\end{abstract}

Keywords: Irrational, FDCs, Geriatrics, Observational study

\section{INTRODUCTION}

Fixed dose combination (FDC) is a combination of two or more than two drugs in a single formulation. ${ }^{1}$ FDCs are acceptable only when the dosage of each ingredient meets the requirement of a defined population group and when the combination has a proven advantage over single compound administered separately in therapeutic effect, safety or compliance.

The development of fixed-dose combinations (FDCs) is becoming increasingly important from a public health perspective. They are being used in the treatment of a wide range of conditions and are particularly useful in the management of human immunodeficiency virus/acquired immunodeficiency syndrome (HIV/AIDS), malaria and tuberculosis, which are considered to be the foremost infectious disease threats in the world today.

The FDC was termed as rational if they had: (WHO guidelines) ${ }^{2}$

- Active pharmaceutical ingredients (APIs) with complementary mechanism of action

- Decrease the occurrence of resistance for antimicrobial agents (antimicrobial agents)

- Increase the efficacy of the combination 
- Decrease the occurrence of adverse drug reactions or toxicity

- Increase the compliance of the drug therapy with decrease pill burden

- Decrease the total cost of the therapy

- Dose of each API should be appropriate for defining or larger groups of populations.

But the bitter fact is that, majority of the FDCs do not fulfill any of the above criteria's, hence making them irrational for usage. The most pressing concern with irrational FDCs is that they expose patients to unnecessary risk of adverse drug reactions.

Prescription of these FDCs in geriatric population has become a matter of concern. The elderly population is increasing rapidly worldwide. At present, India is the third country after China and USA with large elderly population in the world. $^{3}$ Presence of multiple comorbidities in elderly people requires use of multiple medications which increase the irrational prescription, noncompliance, economic burden, adverse drug reactions and drug interactions. ${ }^{4}$ Prescription of irrational FDCs in such geriatric population may have huge impact mainly on their health. Irrational FDCs hastens the above complications in the elderly populations.

Many unapproved and irrational formulations of FDCs are available in India. Most popular and highly profitable among them are analgesics, antibiotics, multivitamins, and cough and cold preparations. There is a growing concern about increasing popularity of irrational FDCs, which imposes unnecessary financial burden, increase the occurrence of adverse drug reactions, hospitalization and ultimately reducing the quality of life. ${ }^{5}$ The concept of rational FDCs has not yet penetrated in the minds of physicians; hence there is a need for evaluation, as large numbers of FDCs are of little importance in terms of effective health care.

Presently, there are few studies on prescription of irrational FDCs in India but studies in geriatric population are lacking. ${ }^{6,7}$ Hence, this cross-sectional study was conducted to assess the prescription rate of irrational FDCs in geriatric patients in our hospital.

The objectives of our study were to Study the prescription rate of FDCs in geriatric patients, to evaluate the rationality of prescribed FDCs by using WHO guidelines, to study whether the prescribed FDCs are mentioned in essential medicines list of WHO 2015 and National list of essential medicines (NLEM) 2015, and study the demographic features and diagnosis of patients in study population. ${ }^{2,8,9}$

\section{METHODS}

A cross sectional observational study was carried out for a period of 2 months at M. S. Ramaiah Hospital, a tertiary care teaching hospital in South India. The case record files of all geriatric patients aged $\geq 60$ years and visiting various departments of our hospital were retrieved from medical records section after obtaining approval from institutional ethics committee (MSRMC/EC/2015).

Based on study done by Rayasam SP et al, it has been observed that $94.6 \%$ of the prescribed FDCs were irrational. In the presente study expecting to get similar results with $2.5 \%$ relative precision and $95 \%$ confidence level, the study requires a minimum of 351 subjects. $^{6}$

We reviewed the prescriptions of above patients and the details were collected during that particular hospital visit. To evaluate the drug prescribing pattern, a specially designed proforma containing relevant details such as demographics (age, gender), clinical data (diagnosis), and drug data was used. Drug data includes drugs prescribed (generic/brand name) with their dose, route and frequency of administration.

The data collected was presented as, age and gender distribution of the study sample, diagnosis, prescription rate of FDCs; number of FDCs prescribed per patient, their rationality (assessed by using WHO guidelines), and whether the prescribed drugs were present in the WHO list of essential medicines 2015 and NLEM-2015. ${ }^{2,8,9}$

SPSS 20 software package was used for all statistical calculations. Descriptive statistics were used to analyse the data. The graphs were prepared using Microsoft Excel package.

\section{RESULTS}

We studied case files of 361 geriatric patients who visited our hospital during our study period. Among 361 patients $212(58.7 \%)$ were male and $149(41.3 \%)$ were female patients. The minimum and maximum age of the patients during the visit was 60 and 93 years respectively. The mean age of our study population was $67.8 \pm 7.2$ years. Respiratory diseases $(27.42 \%)$ are the most common cause for hospital visit followed by genitourinary $(19.94 \%)$ and cardiovascular $(10.52 \%)$, cancer $(8.58 \%)$, and cerebrovascular $(6.92 \%)$ diseases as shown in Table 1 .

Table 1: Patient diagnosis.

\begin{tabular}{|lll|}
\hline Disease & $\begin{array}{l}\text { No. of Patients } \\
(\mathbf{n = 3 6 1 )}\end{array}$ & $\begin{array}{l}\text { Percentage of } \\
\text { patients }(\%)\end{array}$ \\
\hline Respiratory & 99 & 27.42 \\
\hline Genitourinary & 72 & 19.94 \\
\hline Cardiovascular & 38 & 10.52 \\
\hline Cancer & 31 & 8.58 \\
\hline Cerebrovascular & 25 & 6.92 \\
\hline Gastrointestinal & 22 & 6.09 \\
\hline Viral fever & 20 & 5.54 \\
\hline Hematological & 09 & 2.49 \\
\hline Bone and Joint & 07 & 1.93 \\
\hline Liver & 06 & 1.66 \\
\hline Others & 32 & 8.86 \\
\hline
\end{tabular}


In our study out of 361 patients, 252 (69.8\%) patients received FDCs. The number of FDCs prescribed per patient was ranging from one to six. Around $39.7 \%$ patients received one FDC, $34.9 \%$ patients two FDCs and $25 \%$ received three or more than three FDCs as shown in Figure 1. Of the 252 FDCs prescribed, by excluding the inter-departmental repetitions and different brands of the same FDC, the total numbers of the FDCs which were considered for further analysis was 82. The pharmacological classes of FDCs prescribed were depicted in Table 2.

Table 2: Pharmacological classes of FDCs.

\begin{tabular}{|llcl|}
\hline Drug Class & Total FDCs prescribed (n=82) & Rational Irrational \\
\hline $\begin{array}{l}\text { Cardiovascular FDCs (anti-hypertensives, antiplatelet } \\
\text { agents, hypolipidemics) }\end{array}$ & 14 & 09 & 05 \\
\hline Multivitamins & 12 & 00 & 12 \\
\hline $\begin{array}{l}\text { Respiratory FDCs (anti-asthmatic drugs, cough and cold } \\
\text { preparations) }\end{array}$ & 12 & 05 & 07 \\
\hline Antimicrobials & 10 & 05 & 05 \\
\hline Analgesics & 09 & 00 & 09 \\
\hline $\begin{array}{l}\text { Gastrointestinal FDCs (anti-ulcer rugs, anti-spasmodics, } \\
\text { laxatives, anti-diarrheal drugs) }\end{array}$ & 08 & 01 & 07 \\
\hline Antidiabetics & 06 & 02 & 04 \\
\hline FDCs used in BPH & 04 & 00 & 04 \\
\hline Calcium and vitamin combinations & 03 & 01 & 02 \\
\hline Iron+folic acid combinations & 02 & 02 & 00 \\
\hline FDCs in CNS diseases (anti-parkinsonian drugs) & 01 & 01 & 00 \\
\hline Others & 01 & 00 & 01 \\
\hline
\end{tabular}

Table 3: Prescribed FDCs present in WHO essential medicines list-2015 and national list of essential medicines2015.

\begin{tabular}{|ll|}
\hline $\begin{array}{l}\text { Prescribed FDCs present in WHO essential medicines } \\
\text { list - } 2015\end{array}$ & $\begin{array}{l}\text { Prescribed FDCs present in national list of essential } \\
\text { medicines } \mathbf{2 0 1 5}\end{array}$ \\
\hline Amoxicillin+clavulanic acid & Amoxicillin+clavulanic acid \\
\hline Imipenem+cilastatin & Piperacillin+tazobactum \\
\hline Trimethoprim+sulfamethoxazole & Trimethoprim+sulfamethoxazole \\
\hline Ferrous salt+folic acid & Ferrous salt+folic acid \\
\hline Oral rehydration salt & Oral rehydration salt \\
\hline Levodopa+carbidopa & Levodopa+carbidopa \\
\hline & Premix insulin \\
\hline
\end{tabular}

Table 4: Rational FDCs prescribed.

\begin{tabular}{|ll|}
\hline Pharmacological class & FDCs prescribed \\
Anti-hypertensive & $\begin{array}{l}\text { Losartan/telmisartan/olmesartan+hydrochlorothiazide, } \\
\text { Atenolol/metoprolol+amlodipine, Amlodipine+telmisartan, } \\
\text { Furosemide/torsemide+spironolactone }\end{array}$ \\
\hline Drugs used in angina and heart failure & Isosorbide dinitrate+hydralazine hydrochloride \\
\hline Anti-platelet agents & Aspirin+clopidogrel \\
\hline Antimicrobial agents & $\begin{array}{l}\text { Amoxicillin+clavulanic acid, Piperacillin+tazobactum, } \\
\text { Cefaperazone+sulbactum, Trimethoprim+sulfamethoxazole, } \\
\text { Imipenem+cilastatin }\end{array}$ \\
\hline Anti-diabetic agents & Premix Insulin \\
\hline Anti-anemic agents & Ferrous sulphate+folic acid, Ferrous ascorbate+folic acid \\
\hline Calcium and vitamin preparations & Calcium+vitamin D \\
\hline Anti-parkinsonian drugs & Levodopa+carbidopa \\
\hline Anti-diarrheal drugs & Oral rehydration salt \\
\hline Drugs used in cough and cold & Ambroxol+guaiphenesin+salbutamol, Terbutaline+bromhexine+guaiphenesin \\
\hline
\end{tabular}


Drugs used in COPD and antiasthmatic drugs
Inhaler-ipratropium bromide+l-salbutamol,

Inhaler-salmeterol/formoterol+fluticasone, Etophylline+theophylline hydrate

Table 5: Irrational FDCs prescribed.

\begin{tabular}{|ll|}
\hline Pharmacological class & FDCs \\
\hline Antihypertensive agents & Metoprolol+ramipril, Amlodipine+hydrochlorothiazide \\
\hline Hypolipidemic agents with Antiplatelet agents & Atorvastatin+clopidogrel, Rosuvastatin+aspirin \\
\hline \multirow{3}{*}{ Analgesics } & $\begin{array}{l}\text { Tramadol+paracetamol } \\
\text { Diclofenac/ibuprofen/naproxen/aceclofenac/etodolac+paracetamol } \\
\text { Diclofenac+serratiopeptidase, Diclofenac+chymotrypsin }\end{array}$ \\
\hline \multirow{2}{*}{ Antimicrobial agents } & $\begin{array}{l}\text { Ciprofloxacin+tinidazole,Ofloxacin+ornidazole, } \\
\text { Amoxicillin+cloxacillin, Cefpodoxime proxetil+clavulanic acid } \\
\text { Cefuroxime+clavulanic acid }\end{array}$ \\
\hline Vitamin and Mineral preparations & Multivitamins with minerals \\
\hline Antidiabetic preparations & Glimepiride/glipizide/glimepiride/glibenclamide+metformin \\
\hline Anti-asthmatic agents & Montelukast+levocetrizine \\
\hline & $\begin{array}{l}\text { Dextromethorphan+phenylephrine+chlorpheniramine maleate } \\
\text { Phenylephrine+naphazoline+menthol+camphor }\end{array}$ \\
Drugs used in Cough and Cold & Codeine+chlorpheniramine maleate, \\
& Paracetamol+phenylephrine+cetirizine, Cetirizine+phenylephrine \\
\hline Antiulcer drugs & Omeprazole/rabaprazole+domperidone, Pantoprazole+itopride \\
& Megaldrate+simethicone \\
\hline Laxatives & Liquid paraffin+magnesium hydroxide+sodium picosulphate \\
\hline Antidiarrheal & Lactobacillus+pyridoxine+nicotinamide \\
\hline Drugs used in Benign prostatic hypertrophy & Alfuzosin/tamsulosin/silodosin+dutasteride, Tolterodine+tamsulosin \\
\hline Calcium with Vitamins & Vitamin D+calcium+vitamin K \\
\hline Others & Calcium citrate+vitamin D3+magnesium hydroxide+zinc sulphate \\
\hline
\end{tabular}

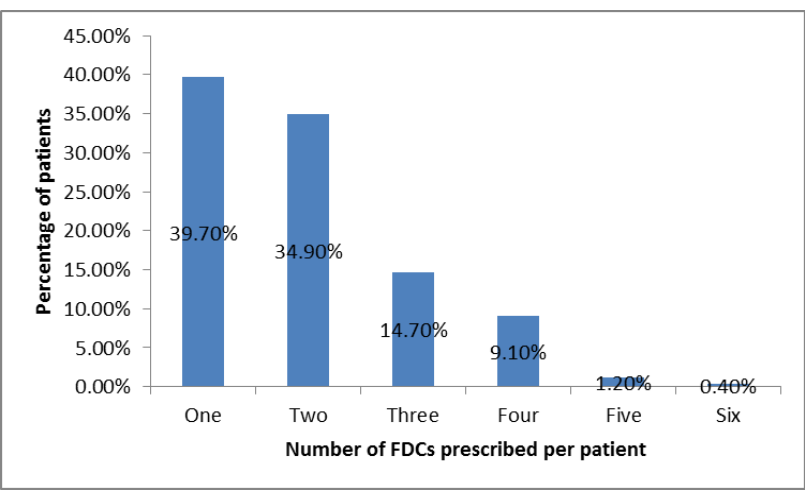

Figure 1: Number of FDCs prescribed per patient.

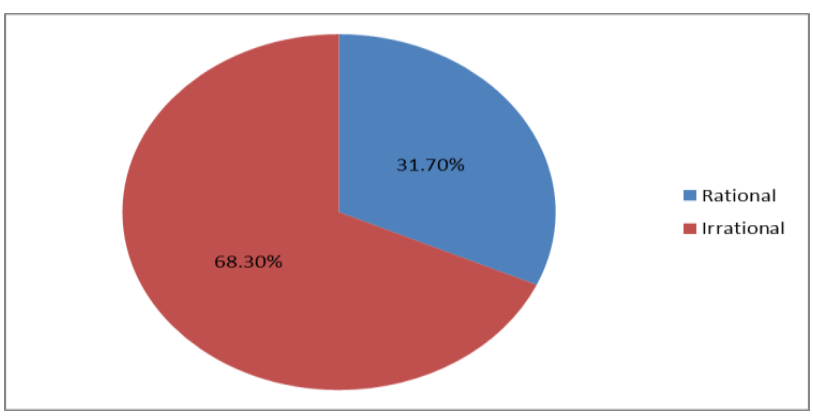

Figure 2: Percentage of rational and irrational FDCs.
Among the 82 prescribed FDCs in our study, only 6 were present in WHO list of essential medicines 2015 and 7 were in national list of essential medicines 2015 as depicted in Table 3 . Of the 82 FDCs prescribed, only 26 $(31.7 \%)$ were rational and the remaining $56(68.3 \%)$ FDCs were irrational as per WHO guidelines as depicted in Figure 2. The different pharmacological classes of rational and Irrational FDCs prescribed in our study are listed in Table 4 and Table 5.

\section{DISCUSSION}

Our study evaluated the rationality of FDCs prescribed in geriatric patients in a tertiary care hospital in South India. In our study the prescription rate of FDCs was $69.8 \%$ which is very high when compared to $17.87 \%$ in a study conducted by Jhaveri BN et al. ${ }^{3}$ The total number of FDCs prescribed after excluding inter-departmental repetitions and the different brands of the same drug was 82. Majority of the patients received one or two FDCs, but around 64 patients received three or more than three FDCs which is again a matter of great concern as majority of the FDCs prescribed were irrational.

The commonly prescribed FDCs in our study were combination of Ipratropium bromide+L-salbutamol 
inhaler, multivitamin preparations, antihypertensive combinations, anti-platelet agents, combination of diclofenac, ibuprofen, naproxen, aceclofenac, etodolac with paracetamol, antimicrobial agents, intermediate acting insulins, combination of Proton pump inhibitors with prokinetic agents. In a study done by Rayasam et al, antimicrobial, anti-inflammatory, nutritional supplements, cough and cold agents were the commonly prescribed FDCs. ${ }^{6}$ This difference in prescription pattern may be due to the fact that in our study we included only geriatric patients, but they have included patients of all age groups. The prescription of combination of ipratropium bromide + L-salbutamol inhaler was more in our study, as many geriatric patients had respiratory diseases such as chronic obstructive pulmonary disease and bronchial asthma.

The WHO list of essential medicines has a total of 29 FDCs, among the 82 FDCs prescribed in our study, only 6 FDCs are present in WHO model list. ${ }^{8}$ The national list of essential medicines has 21 FDCs, among the 82 FDCs prescribed in our study; only 7 FDCs are in national list of essential medicines. ${ }^{9}$

Of the 82 FDCs prescribed in our study majority $(68.3 \%)$ were irrational. Only 26 FDCs prescribed in our study were rational. In many FDCs prescribed in our study, pharmacokinetic features of the individual components did not match, individual components were not having complementary mechanism of action, efficacy of the combination was not high when compared with same components when given separately, and there was an increase in adverse effects. So, they did not fulfill the WHO criteria. ${ }^{2}$

Among the 56 irrational FDCs prescribed in our study, we are discussing the reason for irrationality for few combinations. In the treatment of diarrhoea, a combination of fluoroquinolones (ciprofloxacin, ofloxacin) with antiamoebic agents (tinidazole, ornidazole) is commonly used, but this is irrational because most of the times diarrhoea is either bacterial or amoebic but never mixed infection and using this combination will add to cost, adverse effects and resistance. $^{1}$ The combination of amoxicillin with cloxacillin is commonly used which is again an irrational combination as amoxicillin is inactive against staphylococcus and cloxacillin is not so active against streptococci. For any given infection, one of the components is useless but adds to cost and adverse effect. Since amount of each drug is halved, efficacy is reduced and chances of selecting resistant strains are increased. ${ }^{1}$ The combinations of cephalosporins with clavulanic acid are irrational as cephalosporins are inactivated by class I beta lactamases or cephalosporinases while clavulanic acid is only active against class II to class $\mathrm{V}$ beta lactamases. $^{10}$

In patients with gastroesophageal reflux disease, the use of combination of pantoprazole with itopride has shown no additional benefit. FDCs of domperidone+rabeprazole, the role of prokinetics like domperidone is not clear as peptic ulcer disease is not always associated with nausea and vomiting and there is an increased incidence of rhabdomyolysis. ${ }^{1,11}$

Combination of two nonsteroidal anti-inflammatory drugs (diclofenac, naproxen, etodolac) with paracetamol was commonly used in our study, but when both are added the increase in efficacy is not much. ${ }^{12}$ FDCs of diclofenac+serratopeptidase do not offer any particular advantage over the individual drugs despite the claim that serratopeptidase promotes more rapid resolution of inflammation. ${ }^{13}$ Dicyclomine and paracetamol combination is highly irrational as paracetamol promotes sweating and thereby helps in heat dissipation. On the other hand, the dicyclomine inhibits sweating. Use of this combination may cause hyperthermia. ${ }^{13}$ FDCs of second generation sulfonylureas with metformin were commonly practiced in our study, but this is not rational because second generation sulfonylureas need to be administered before the meals and metformin is to be administered after the meals. ${ }^{14}$ In our study many patients received FDCs of vitamins with mineral preparations. When we assessed the individual components individual vitamins are not present in adequate amounts and adding minerals with vitamins is not useful. ${ }^{15}$

The combination of montelukast with levocetrizine is not rational, as montelukast sodium is alkaline and stable, levocetrizine dihyrochloride is acid stable, when we prepare a matrix tablet both drugs would be in contact and make it unstable during the shelf life of formulation. Hence it is recommended to prepare bilayer tablet, as it improves and increases the stability of both the drugs in combination. ${ }^{16}$ Many irrational cough and cold remedies containing central cough suppressants with antihistaminics and alpha agonists were prescribed in our study.

Many irrational combinations of antihypertensive drugs were prescribed in our study. Combination of a beta blocker (metoprolol) with angiotensin converting enzyme inhibitors (ramipril) is not rational, as beta blockers inhibit renin secretion, cause sodium retention and peripheral vasoconstriction. ACE inhibitors may be less effective in this low renin state. ${ }^{17}$ The combination of CCBs (amlodipine) with thiazide diuretics has no advantage as CCBs have natriuretic properties and so possibly attenuate the effect of thiazides. ${ }^{17}$ Combination of statins with antiplatelet agents is also not correct as statins attenuate the antiplatelet activity of clopidogrel by competing through cytochrome pathway metabolism. ${ }^{18}$ Combination of selective $\alpha$ blockers (alfuzosin, tamsulosin, siladosin) with 5- $\alpha$ reductase inhibitors (dutasteride) is commonly used in the treatment of benign prostatic hypertrophy, but this is not rational as their pharmacokinetics do not match and there is no additional benefit of these combinations when administered separately. ${ }^{19}$ 
In our study a few rational anti-hypertensive FDCs were prescribed. The combination thiazide diuretics (hydrochlorothiazide) with angiotensin receptor blockers (losartan, telmisartan, olmesatan) were commonly used in the treatment of hypertension. This combination will increase the antihypertensive efficacy as activation of renin angiotensin-aldosterone system (RAAS) by hydrochlorothiazide enhances the effects of agents acting through blockade of this pathway. ${ }^{17}$ A combination of dihydropyridine CCBs (felodipine, amlodipine) with beta blockers (metoprolol, atenolol) is also beneficial in the treatment of hypertension as beta blockers suppress renin secretion which potentiates the vasodilatory properties of CCBs. The combination has shown significant long term decrease in blood pressure. The acute adverse hemodynamic effect of beta blocker may be reduced when amlodipine is added. Fatigue associated with beta blockers can be reduced when combined with amlodipine. But evidence regarding the efficacy and safety of this combination is lacking. The combination of amlodipine with telmisartan also increases the anti-hypertensive efficacy. The likelihood of development of pedal edema with amlodipine is decreased when combined with ARBs. ${ }^{17}$ The combination of furosemide with spironolactone is also demonstrated an increase in efficacy in the treatment of hypertension as hypokalemia produced by furosemide is controlled by spironolactone and the dose of spironolactone is reduced in the combination when compared to monotherapy. ${ }^{20}$ Hydralazine alone or nitrate alone has not proven useful in the treatment of chronic heart failure. However, when combined they supplement each other and nitrate tolerance is attenuated by hydralazine. ${ }^{21}$

The combination of clopidogrel with aspirin significantly reduces collagen - induced platelet aggregation compared with both monotherapies, suggesting a synergistic platelet inhibitory effect. But a major drawback of this combination is increased risk of bleeding which should be monitored. ${ }^{22}$

In our study FDCs Levo-salbutamol with ipratropium bromide and salmeterol /formoterol with fluticasone inhalers were commonly used. The use of these FDCs resulted in increase in efficacy, improved the compliance, and reduced the cost of therapy in patients with chronic obstructive pulmonary disease and bronchial asthma. ${ }^{23}$

The combination of beta lactum antibiotics (amoxicillin, piperacillin, cefaperazone) with beta lactamase inhibitors (clavulanic acid, tazobactum, sulbactum) is beneficial as beta lactamases re-establishes the activity of beta lactums against betalactamase producing resistant bacteria. ${ }^{10}$ The main drawback of imipenem is it gets hydrolyzed by the enzyme dehydropeptidase I in the renal tubules. This can be prevented by combining it with cilastatin, a reversible inhibitor of dehyropeptidase I. Combining imipenem with cilastatin will improve the antibacterial efficacy of the imipenem. $^{10}$ The combination of trimethoprim with sulfamethoxazole is synergistic in nature as they cause sequential blockade of folate metabolism. When given as monotherapy both are bacteriostatic in nature but when given as FDC, it is bactericidal in nature. 8,9

The combination of calcium with vitamin D3 is rational, as vitamin D3 helps in absorption of calcium. The combination of levodopa with carbidopa is also commonly used in the treatment of parkinsonism. Carbidopa inhibits the peripheral decarboxylation of levodopa and improves its bioavailability. Some of the other rational FDCs prescribed in our study were combination of ferrous salts with folic acid which is used in the treatment of anemia, oral rehydration salt (ORS) used in the treatment of diarrhea, premix insulins used in the treatment of diabetes mellitus. ${ }^{8,9}$

\section{CONCLUSION}

In the present study we assessed the prescription rate of irrational FDCs prescribed in geriatric patients of a tertiary care hospital in south India. The prescription rate of irrational FDCs is very high even in our hospital. There is a need to educate physicians regarding such irrational FDCs, so that we can reduce the use of such combinations. We also need to teach the undergraduate and postgraduate medical students about the rational use of FDCs. Drug regulatory authorities should take serious measures to prevent entry of such irrational FDCs in to the market. This will ultimately help us to improve the quality of our prescriptions and prevents unnecessary financial burden, occurrence of ADRs and ultimately improves the quality of life of geriatric patients.

\section{ACKNOWLEDGEMENTS}

This is an ICMR - STS Project funded by ICMR. We would like to thank ICMR for funding our study.

\section{Funding: ICMR \\ Conflict of interest: None declared \\ Ethical approval: The study was approved by the Institutional Ethics Committee (MSRMC/EC/2015)}

\section{REFERENCES}

1. Gautam CS, Aditya S. Irrational drug combinations: Need to sensitize undergraduates. Indian J Pharmacol. 2006;38:169-70.

2. WHO technical report series. WHO expert committee on specifications for pharmaceutical preparationsthirty ninth report. Geneva: WHO, 2005. Available at apps.who.int/prequal/info_general/documents/trs929/ who_trs_929.pdf. Accessed 24 November 2014.

3. Jhaveri BN, Patel TK, Barvaliya MJ, Tripathi CB. Drug utilization pattern and pharmacoeconomic analysis in geriatric medical in-patients of a tertiary care hospital of India. J Pharmacol Pharmacotherapy. 2014;5:15-20. 
4. Gorzoni ML, Fabbri RM, Pires SL. Potentially inappropriate medications in elderly. Rev Assoc Med Bras. 2012;58:442-6.

5. Baiardini I, Guerra L, Pasquali M, Bonadonna P, Pasalaqua G, Canonica GW. Quality of life in patients with adverse reactions to drugs: preliminary results from a new questionnaire. J Allergy Clin Immunol. 2004;113(2):s70.

6. Rayasam SP, Dudhgaonkar SS, Dakhale GN, Hire RC, Deshmukh PS, Gaikwad NN. The irrational fixed dose combinations in the Indian drug market: an evaluation of prescribing pattern using WHO guidelines. Int J Basic Clin Pharmacol. 2013;2:452-7.

7. Devi M, Sriram S, Rajalingam B, Anthraper AR, Varghese RS, Phani VA. Evaluation of the rationality of fixed dose combinations of cardiovascular drugs in a multispecialty tertiary care hospital in Coimbatore, Tamilnadu, India. Hygeia J D Med. 2012;4(1):51-8.

8. $19^{\text {th }}$ WHO Model List of Essential Medicines, 2015. Available

at http://www.who.int/medicines/publications/pharmaco poeia. Accessed 24 November 2014.

9. National list of essential medicines of India, 2015. Available at http://www.cdsco.nic.in. Accessed 1 March 2016.

10. Betalactum antibiotics. In: Tripathi KD eds. Essentials of Medical Pharmacology. $7^{\text {th }}$ ed. New Delhi, Jaypee Brothers Medical Publishers (P) LTD; 2013:716-732.

11. Dhaneria SP. Rational and irrational drug combinations. Drug Bulletin. 2010;35(2):1-15.

12. Hiller A, Silvanto M, Savolainen S, Tarkkila P. Paracetatamol and diclofenac alone and in combination for analgesia after elective tonsillectomy. Acta Anaesthesiol Scand. 2004;48(9):1185-9.

13. Amitava S. Indian market's fixation with fixed dose combinations. Rational Drug Bulletin. 2002;12:1.
14. Sreedhar D, Subramanian G, Udupa N. Combination drugs: are they rational? Curr Sci. 2006;91:406.

15. Rational use of medicines. Good pharmacy practice I.P.A. - C.D.S.C.O. - W.H.O. India country office. Available at http://www.whoindia.org/LinkFiles/ GPP Rational Use of Medicines.pdf. Accessed 3 August 2010.

16. Rathod RT, Misra D. FDC of montelukast with levocetirizine: focus on bilayer technology. J Ind Med Ass. 2009;107(8):562-4.

17. Stanon T, Reid JL. Fixed dose combination therapy in the treatment of hypertension. Journal of Human Hypertension. 2002;16:75-8.

18. Goeng BK, Jeong KK, Sul P, Jai JJ, Hyung SY, Sang $\mathrm{HK}$, et al. Effect of atorvastatin and clopidogrel coadministration after coronary stenting in Korean patients with stable angina. Korean Cardiology J. 2011;41:28-33.

19. Antiadrenergic drugs. In: Tripathi KD eds. Essentials of Medical Pharmacology. $7^{\text {th }}$ ed. New Delhi, Jaypee Brothers Medical Publishers (P) LTD; 2013:143-4.

20. Anastasios M, Maria S, Dimitris PP. Resistant hypertension workup and approach to treatment. International Journal of Hypertension. 2011;2011:598694.

21. Cardiac glycosides and drug for heart failure. In: Tripathi KD eds. Essentials of Medical Pharmacology. $7^{\text {th }}$ ed. New Delhi, Jaypee Brothers Medical Publishers (P) LTD; 2013:522-3.

22. Moshfegh K, Redondo M, Julmy F, Wuillemin WA, Gebauer MU, Haeberli A, et al. Antiplatelet effects of clopidogrel compared with aspirin after myocardial infarction: enhanced inhibitory effects of combination therapy. J Am Coll Cardiol. 2000;36(3):699-705.

23. Donohue JF. Combination therapy for chronic obstructive pulmonary disease. Proceedings of the American Thoracic Society. 2005;2:272-81.

Cite this article as: Dakappa A, Narayanareddy M. A cross-sectional study to assess the rationality of fixed dose combinations prescribed in geriatric patients in a tertiary care hospital. Int J Basic Clin Pharmacol 2016;5:1441-7. 